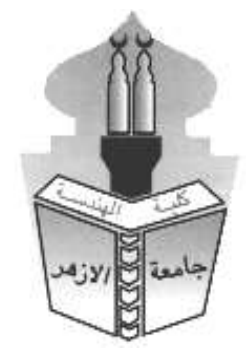

\title{
EFFECT OF NANO SIC PARTICLES ON THE CHARACTERIZATION OF SIC/CU NANO-COMPOSITE
}

\author{
M.A. Metwally ${ }^{1}$, M. M. Sadawy ${ }^{2}$, M. Ghanem ${ }^{3}$, I. G. El-Batanony ${ }^{4}$ \\ ${ }^{1}$ Egyptian Natural Gas Company (GASCO), Cairo, Egypt. \\ ${ }^{2}$ Mining and Pet. Dept., Faculty of Engineering, Al-Azhar University, Nasr City, Cairo, Egypt. \\ ${ }^{3}$ Industrial Education, Suez University, Suez, Egypt. \\ ${ }^{4}$ Mech. Eng. Dept. Faculty of Engineering, Al-Azhar University, Nasr City, Cairo, Egypt.
}

*Corresponding Author E-mail: mtayea00@gmail.com

\begin{abstract}
In the present investigation, the influence of nano-SiC on characterization of $\mathrm{SiC} / \mathrm{Cu}$ nano-composite was investigated. Electron microscope (SEM) was used for microstructure and morphology examinations. The erosion properties were investigated using pin on disc technique in oil environment. The results indicated that the grain structure of the copper matrix was reduced with increasing $\mathrm{SiC}$ nano-particles. The erosion resistance increased by increasing nano-SiC content to 5, 10, 15 and 20 (vol. \%) respectively. Furthermore, the study was also extended to examine the influence of $\mathrm{SiC}$ content on the nuclear properties using winXCom computer program (version 3.1). It was found that there is no a significant variation in nuclear properties of $\mathrm{Cu}$ when the $\mathrm{SiC}$ is incorporated into the matrix at al 1 percentages.
\end{abstract}

KEYWORDS: Powder metallurgy; Composites; Erosion; Fusion reactors.

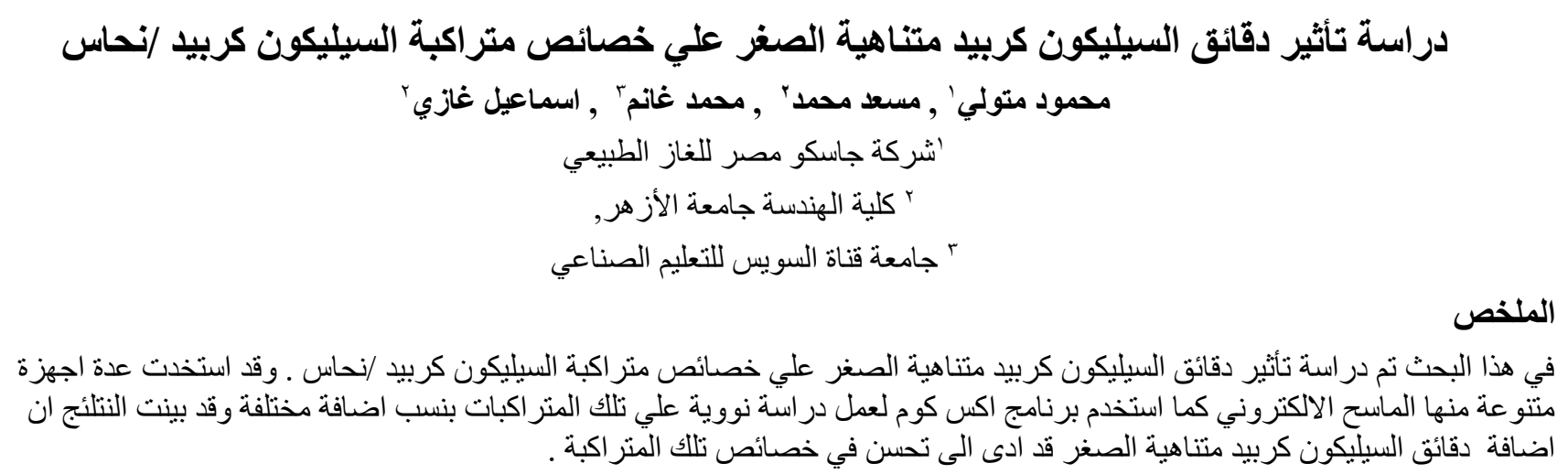




\section{EFFECT OF NANO SIC PARTICLES ON THE CHARACTERIZATION OF SIC/CU NANO-COMPOSITE}

\section{INTRODUCTION}

Copper-based alloys in magnetic containment thermonuclear fusion reactors have been considered as candidate materials for the first wall and stabilizers for superconducting coils [1-3]. In reactor designs that feature high thermal loads on the first wall, their use as a first wall material has been suggested. For highly-loaded divertor collector plates, other designs use copper as a heat sink, in conjunction with other materials. Compared to traditional alloys big value of copper-based alloys [4]. Further many authors reported that copper is an ideal container material because of its thermal stability under the anaerobic conditions [5]. The development of heat sink materials with high thermal conductivity and sufficient strength under the service loading is required for the efficiency of future fusion reactors [6]. Improving the mechanical properties has been a major goal in recent years for the copper alloys. A very favorable class of copper alloys for the above applications is incorporating hard particles into copper matrix. Incorporating hard particles into metal matrix block the movement of dislocation which has a pronounced strengthening effect [6]. Aghamiri et al. [7] found that incorporating $\mathrm{Y}_{2} \mathrm{O}_{3}$ Nano sized into copper matrix improved the mechanical properties of copper to be used in fusion material application. It is known that the hard particles ceramic materials can be incorporated into the metal matrix using casting and powder techniques. However, few new techniques such as electroforming and thermal spraying have also been used to fabricate Cu composites [8]. The powder route can be considered as the most economical rout due to providing uniform distribution of reinforcement particles into the matrix without agglomeration problems. [9]. Among the reinforcements used in fabrication of metal matrix composites, $\mathrm{SiC}$ particles are a potential reinforcement for $\mathrm{Cu}$ owing to their unique properties such as excellent resistance to oxidation and corrosion, high hardness, low coefficient of thermal expansion and low cost [5]. Yunlong et al. [10] investigated the effect of $\mathrm{SiC}$ on the properties of $\mathrm{Cu}$ matrix containing different $\mathrm{SiC}$ content. The results found that the thermal expansion coefficient and the wear resistance of the composites decreased with growing $\mathrm{SiC}$ content. Compared with the pure $\mathrm{Cu}$ matrix, the obtained composites have better wear resistance. Additionally Efe et al. [11] found that incorporating $\mathrm{SiC}$ in copper matrix reduces the electrical conductivity of the matrix. In our previous work [9,12], the obtained results showed that the corrosion resistance of copper increased significantly with increment of $\mathrm{SiC}$ content due to improvement in patina passive film.

In this investigation the influence of $\mathrm{SiC}$ content on the mechanical and abrasion behavior of $\mathrm{Cu}$ composite in oil environments was studied. The study was also extended to examine the influence of SiC content on the nuclear properties using winXCom computer program (version 3.1).

\section{MATERIAL AND METHODS}

\subsection{Material}

$\mathrm{Cu}$ and $\mathrm{SiC}$ nano powders with average particle size of 70 and 50 nano respectively were used in this study. The different $\mathrm{xSiC} / \mathrm{Cu}$ nano-composites were fabricated by powder metallurgy technique whereas, $(\mathrm{x}=5,10,15$ and 20 vol. \%). The powders were mixed together using a mixer with $10 \mathrm{~cm}$ diameter and speed of $950 \mathrm{rpm}$ for $3 \mathrm{~h}$ for obtaining composites with uniform distribution. The powders were cold compacted using universal testing machine at constant pressure of $450 \mathrm{MPa}$ on a disc steel die having a diameter with $12 \mathrm{~mm}$ and a thickness of $10 \mathrm{~mm}$. The green compacted samples were sintered in electric tube furnace at $850{ }^{\circ} \mathrm{C}$ in presence of argon gas for $2 \mathrm{~h}$. more details on the properties of material and fabrication can be found in $[9,12]$.

\subsection{Hardness}

The hardness of the investigated materials was measured using Vicker hardness tester at load of $5 \mathrm{~kg}$. The average value of 10 indentations was reported for each sample.

\subsection{Abrasion Testing}

All the abrasion tests were performed in oil environment using a pin-on-disc machine Fig. 1 at speed of $0.25 \mathrm{~m} / \mathrm{s}$, applied load of 15, abrasive particles of $13 \mu \mathrm{m}$ and time of $30 \mathrm{~min}$. The specimen was in contact with the rotating disc having a diameter of $140 \mathrm{~mm}$. The normal load was applied on the specimen through a cantilever. After each test the specimens were dried, cleaned with a soft brush and weighed. The abrasion rates were calculated using Archard equation $[1 \Upsilon]$ : 


$$
\Delta \mathrm{V}=\mathrm{K} \frac{\mathrm{PL}}{\mathrm{H}}
$$

Where: $\mathrm{V}$ is the loss volume, L- wear distance, P- applied normal load, $\mathrm{K}$-wear coefficient and $\mathrm{H}$ - hardness of material.

\subsection{Gamma Mass Attenuation Coefficients}

The mass attenuation coefficients $\left(\sigma_{\mathrm{Th}}\right)$ data of gamma rays was performed using WinXCom computer program software (Version 3.1) according to Eq. (4) [1 $\left.{ }^{\top}\right]$ :

$$
\sigma_{\mathrm{Th}}=\sum_{\mathrm{i}}^{\mathrm{n}} \mathrm{W}_{\mathrm{i}}\left(\frac{\mu_{\mathrm{i}}}{\rho_{\mathrm{i}}}\right)_{\mathrm{m}}
$$

The Half Value Layer (HVL, cm) is a significant factor in the assessment of the material's shielding efficiency in relation to its thickness per unit. The thickness that attenuates half of the radiation passing through the material refers to HVL. The HVL is derived from the formula below:

$$
\text { Half value layer }(\mathrm{HVL})=\frac{\ln 2}{\mu}
$$
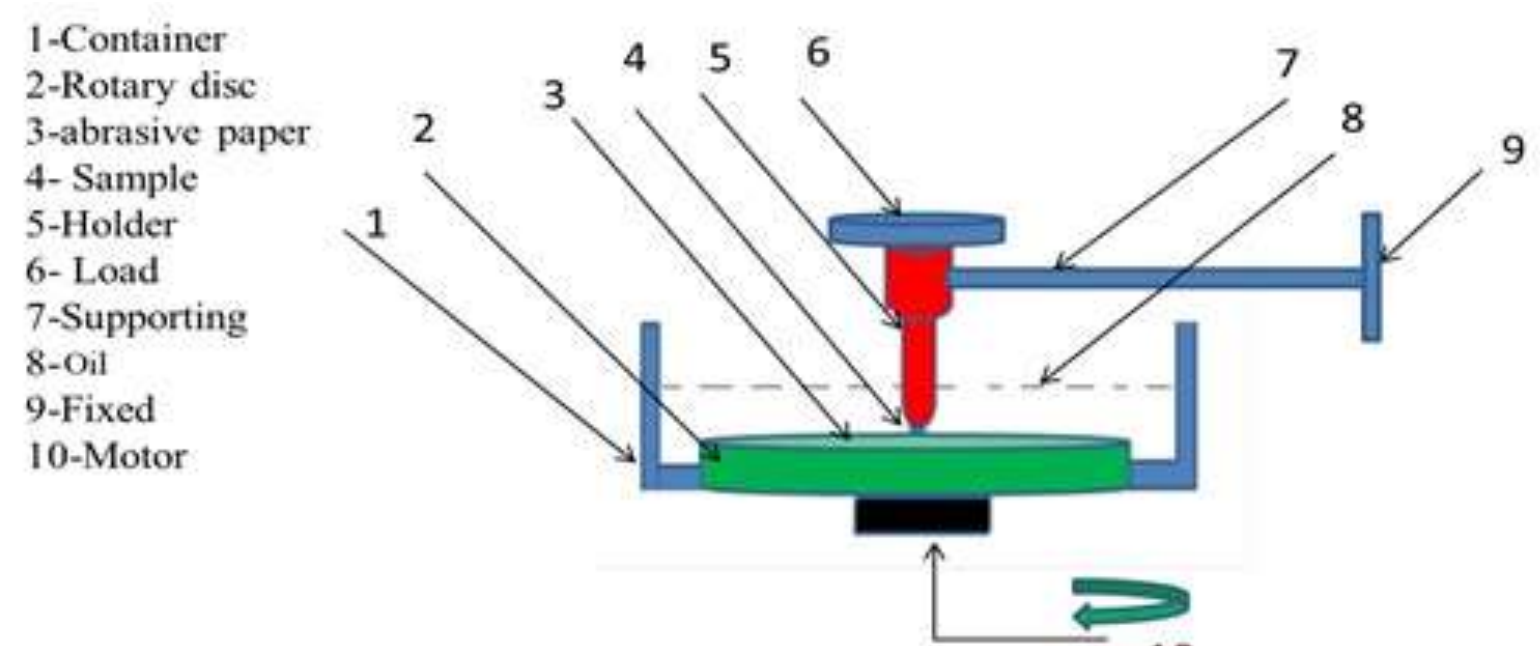

10

Fig. 1: A schematic sketch of wet pin on the disc

Similarly, the tenth value layer (TVL, cm) symbolizes the material thickness, which reduces the passing radiation by a factor of one-tenth of the initial amount. TVL can be calculated using the following equation:

$$
\text { Tenth value layer }(\mathrm{TVL})=\frac{\ln 10}{\mu}
$$

The mean free path (MFP, cm), which is basically the average distance taken by moving particles between two consecutive collusions, is another factor influencing the efficiency of attenuation in radiation shielding. The MFP is calculated based on the following formula:

$$
\text { Mean free path }(\mathrm{MFP})(\lambda)=\frac{\mathbf{1}}{\boldsymbol{\mu}}
$$




\section{EFFECT OF NANO SIC PARTICLES ON THE CHARACTERIZATION OF SIC/CU NANO-COMPOSITE}

Mean free path $(\lambda)=\frac{1}{\mu}$ : The mean free 'path is the average distance a gamma ray travels in the absorber before interacting;

Where: $(\lambda)=\frac{1}{\mu}$ is denotes to the mass attenuation coefficient of the actual element, while Wi is referring to the fractional weight of the element in each sample.

\section{Results And Discussions}

\subsection{Microstructure}

Figure 2 shows the SEM photographs of $\mathrm{SiC} / \mathrm{Cu}$ composites with different $\mathrm{SiC}$ contents after sintering at $900{ }^{\circ} \mathrm{C}$. It clear that the $\mathrm{SiC}$ particles are homogeneously dispersed inside the matrix. Increasing the $\mathrm{SiC}$ content, the $\mathrm{SiC}$ particles move towards the grain boundaries, forming a homogenous network and uniformly dispersed inside the matrix as well. Furthermore, Fig. 2 shows that the grain size of $\mathrm{Cu}$ obviously is reduced with growing $\mathrm{SiC}$ content. This is due to the pinning effect of $\mathrm{SiC}$ that limits the grains growth of the matrix.
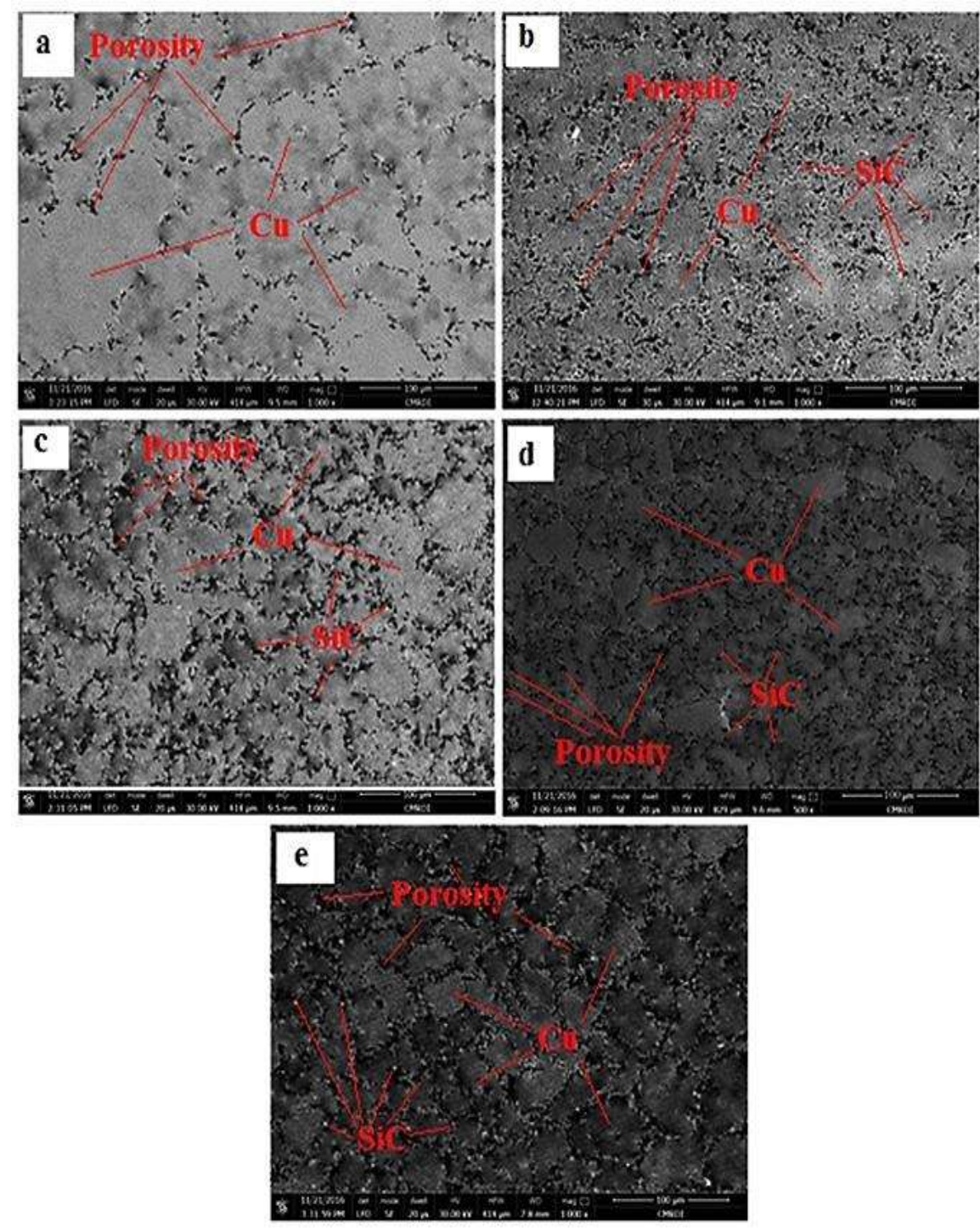

Fig.2: Microstructure of $\mathrm{SiC} / \mathrm{Cu}$ nano-composites with different $\mathrm{SiC}$ contents sintered at $860{ }^{\circ} \mathrm{C}$. (a) 0.0 vol. $\% \mathrm{SiC}$, (b) 5 vol. \% SiC, (c) 10 vol. \% SiC, (d) 15vol. \% SiC and (e) 20 vol. \% SiC 


\subsection{Hardness Measurements}

The hardness value of nano-Cu alloy with different values of nano-SiC content is shown in Fig.3. It is clear that all composite samples indicate higher hardness comparing to $\mathrm{Cu}$ sample. The hardness value increases by $28,39,65$, and $77 \%$ respectively; with an increment of nano-SiC content to 5, 10, 15, and 20 vol. \%, respectively. This trend is due to the difference in the thermal contraction at the interface of $\mathrm{SiC}-\mathrm{Cu}$. This causes a strain field resulting in an increase in the dislocations. Increasing the dislocation reduces the plastic deformation of the composite.

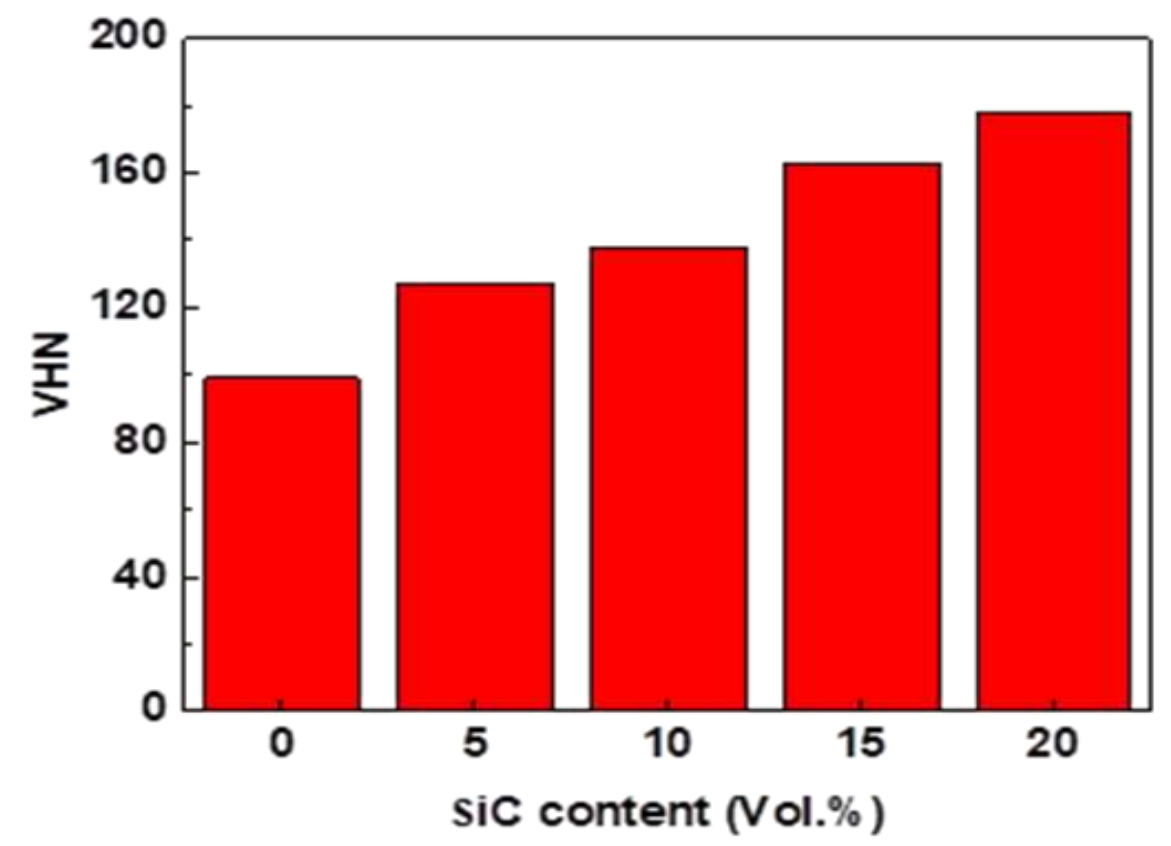

Fig.3: Effect of $\mathrm{SiC}$ content on the hardness of $\mathrm{Cu} / \mathrm{SiC}$ nano composites

\subsection{Effect Of Sic Content On The Abrasion Behavior Of Sic/Cu Composites In Oil Environment}

The effect $\mathrm{SiC}$ content of the abrasion behavior $\mathrm{SiC} / \mathrm{Cu}$ Nano composites in oil environment is shown in Fig. ₹. It is obvious that increasing $\mathrm{SiC}$ content from 5 to 20 (vol. \%), the abrasion rate decreases for all percentages when compared with the base $\mathrm{Cu}$. This enhancement in abrasion resistance is attributed to presence of hard $\mathrm{SiC}$ nanoparticles in the $\mathrm{Cu}$-matrix. These particles act as a load carrier and protect the $\mathrm{Cu}$-matrix from damage. However, it is interesting to note that the gradient of decreasing in abrasion rate depends on the amount of $\mathrm{SiC}$ in the matrix. This is due to the worn surfaces of the investigated alloys are shown in Fig. ${ }^{\circ}$. Clearly the pure $\mathrm{Cu}$ alloy as shown in Fig 2a displays continuous parallel grooves. The behavior suggests that the dominant abrasion mechanism of pure $\mathrm{Cu}$ alloy belongs to the abrasive mechanism [1 $1^{\text {] }}$. Further, Fig. 5a shows that the grooves are wider and deeper suggesting an augmented metallic contact Fig $5 \mathrm{~b}$ shows that $\mathrm{SiC} / \mathrm{Cu}$ composites with $5 \mathrm{SiC}$ (vol \%) suffers from plastic deformation and adhesive wear in several places. Increasing the $\mathrm{SiC}$ to $20 \mathrm{SiC}$ (vol \%), both the plastic deformation and adhesive wear decreased greatly. This behavior may be attributed to many reasons: firstly, a tribo film covers the entire surface and therefore, it decreases the adhesive wear. Secondly, the uniform distribution of $\mathrm{SiC}$ in the matrix. These two factors decrease the adhesive wear. Similar results were obtained in sea water environment for these samples in our previous work [12]. 


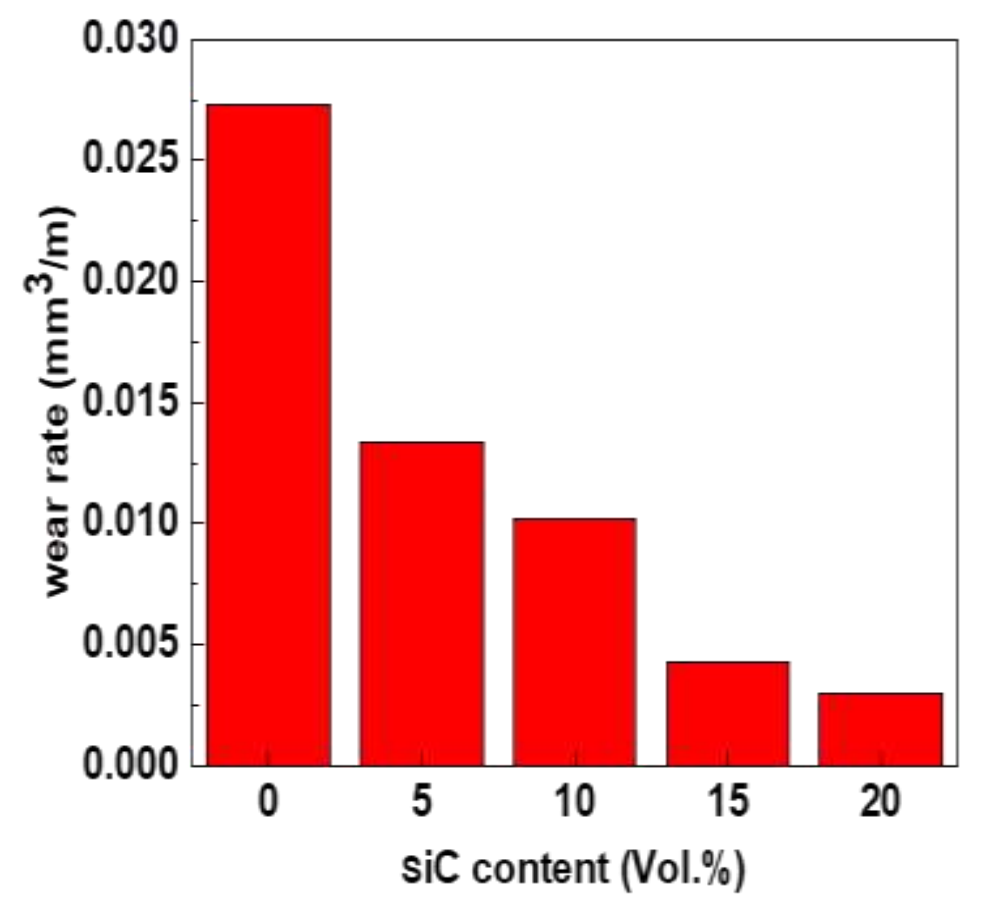

Fig.4: Effect of $\mathrm{SiC}$ content on the abrasion behavior of $\mathrm{Cu} / \mathrm{SiC}$ nano composites

\subsection{Effect Of Sic Content On The Nuclear Radiation Shielding Behavior Of Sic/Cu Composites}

Data on the scattering and absorption of photons (x-rays and gamma rays) are required for many applications in science, engineering, and medicine. The win XCOM program has the ability to generate cross sections on standard energies.

This software provides total cross sections and attenuation coefficients as well as partial cross sections for the following processes: incoherent scattering, coherent scattering, photoelectric absorption, and pair production in the field of the atomic nucleus and in the field of the atomic electrons [1 $\varepsilon$ ]. Therefore, the intensity distribution of gamma rays transmitted through $\mathrm{SiC} / \mathrm{Cu}$ barriers of the investigated samples were calculated and plotted at different incident gamma-ray energy lines as shown in Fig. 6. 

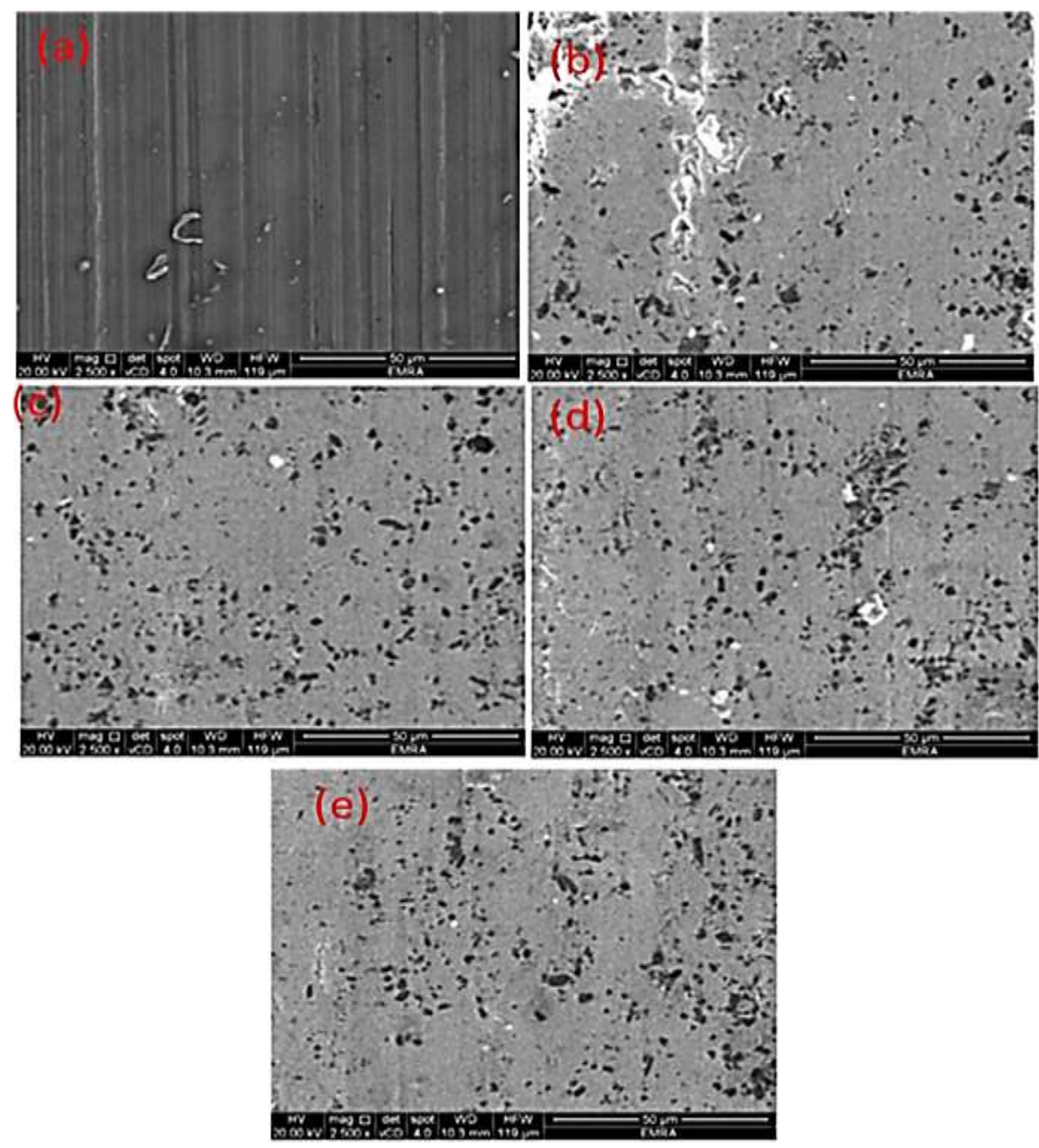

Fig.5: The worn surfaces of the investigated samples after abrasion in the oil 

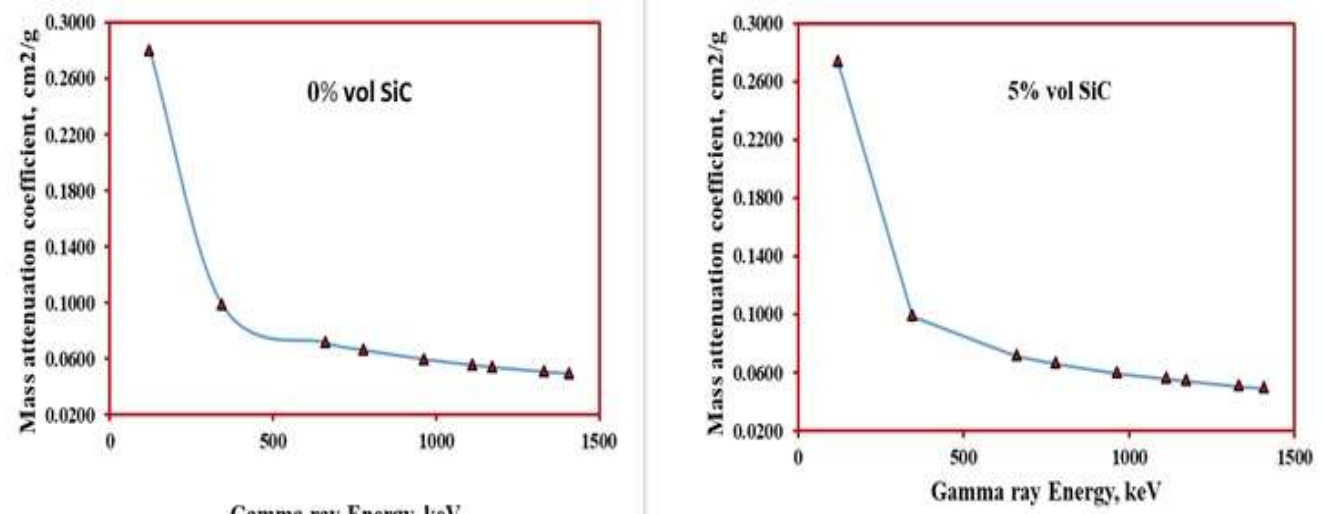

Gamma ray Energy, keV
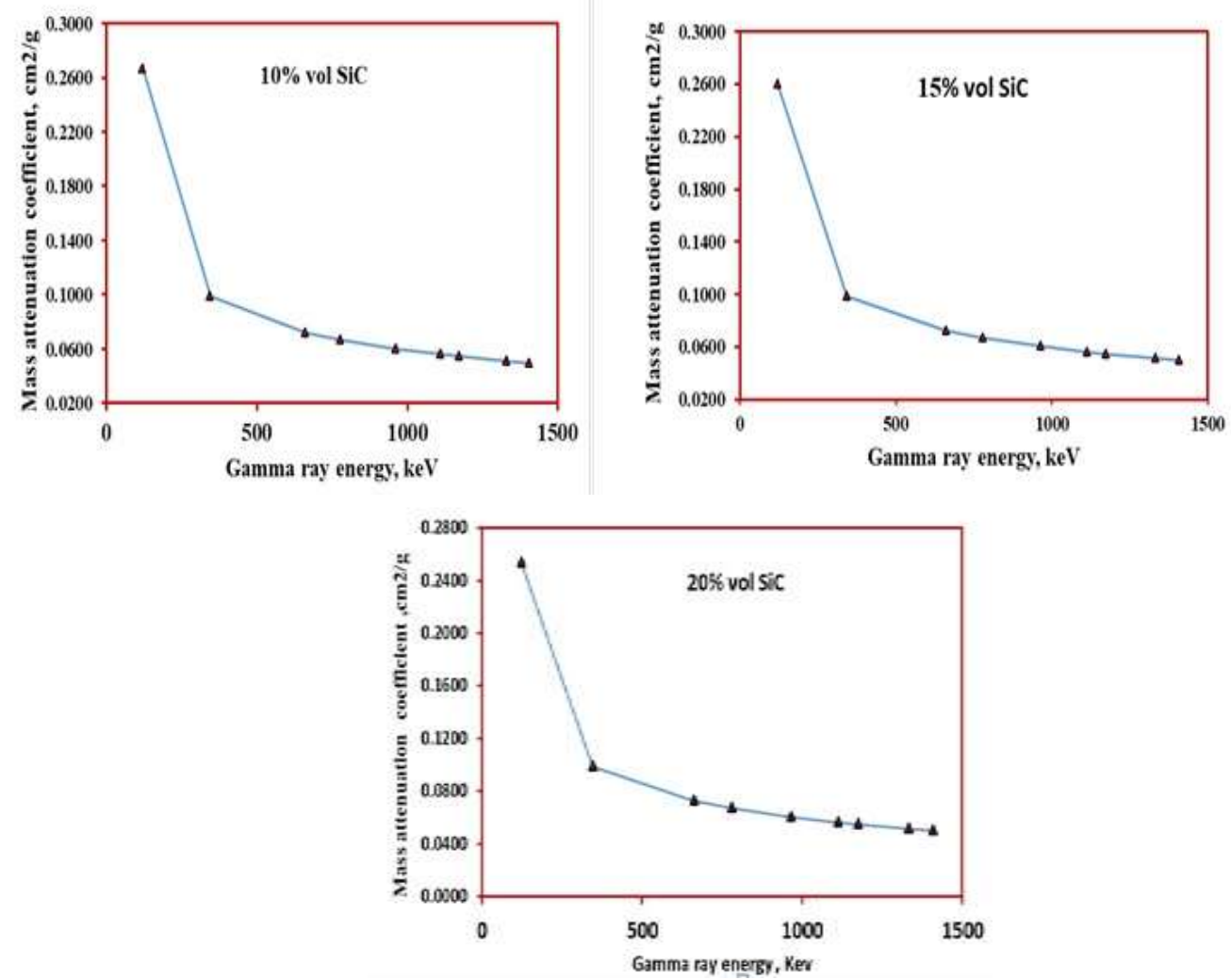

Fig. ': Mass attenuation coefficients of $\mathrm{SiC} / \mathrm{Cu}$ samples as a function of gamma ray energy

Clearly, it can be seen that the behavior of all curves can be separated into two areas. The first area from (121 to 400) keV was ascribed by a sharp reduction in the values of mass attenuation coefficients $(\sigma, \mathrm{cm} 2 / \mathrm{g})$ with the growth of gamma-ray energies. The behavior is due to the photoelectric reaction which predominates among the examined alloy barriers and gamma rays [15]. The second region from (400 to 1407) $\mathrm{keV}$ defines by a slight decrease in the values of mass attenuation coefficients with the increment of gamma-ray energies. This is ascribed to the Compton scattering reaction which predominates in this stage [16]. Further, Fig. $\vee$ shows that the values of $\sigma\left(\mathrm{by} \mathrm{cm}^{2} / \mathrm{g}\right) \mathrm{did}$ not change significantly by increasing the $\mathrm{SiC}$ content up to $1407 \mathrm{keV}$ gamma ray energy. Generally, the values of mass attenuation coefficients directly depend on the density of material. However, in our case our samples still have approximately the same mass attenuation values. This behavior is a good result for many applications. The comparisons of half and tenth value layers of the investigated alloys at the gamma ray energy lines is shown in Tables 1-5 for all investigated samples. The value of mean free paths was also calculated and presented in Tables 1-5. The presented data shows that there is no significant variation in radiation properties of $\mathrm{Cu}$ when the $\mathrm{SiC}$ is incorporated into the matrix at all percentages. 


\section{EFFECT OF NANO SIC PARTICLES ON THE CHARACTERIZATION OF SIC/CU NANO-COMPOSITE}

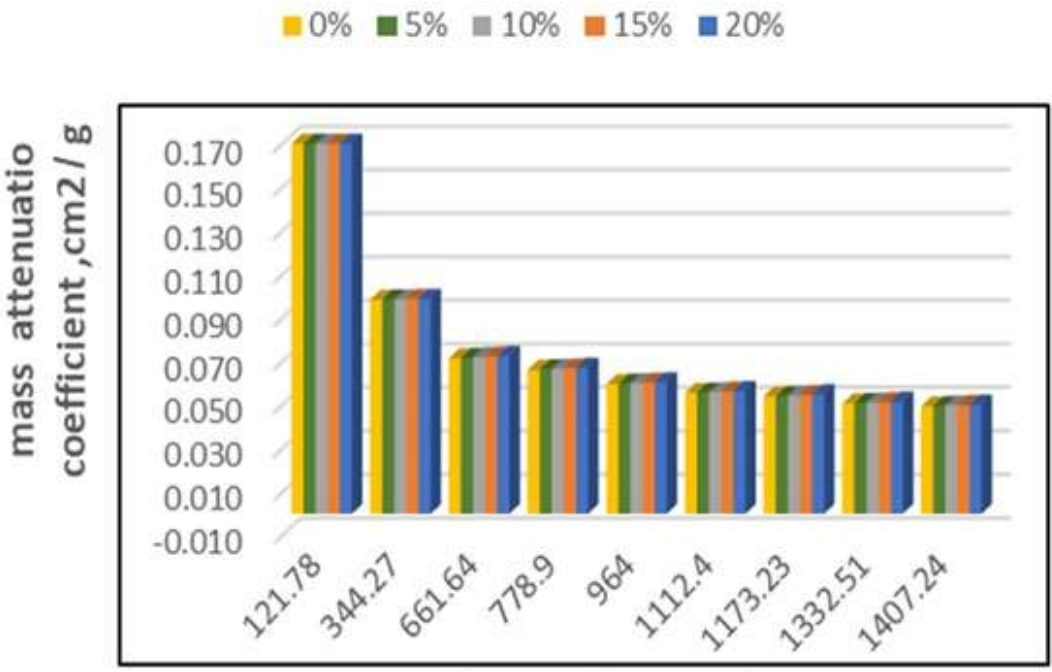

Gamma Energy, kev

Fig.7: Comparison between mass attenuation coefficients of $\mathrm{SiC} / \mathrm{Cu}$ samples with different gamma ray energies

Table 1: Attenuation properties of $\mathrm{Cu}$

\begin{tabular}{|c|c|c|c|c|c|}
\hline $\begin{array}{c}\text { Energy, } \\
\text { keV }\end{array}$ & Linear att. Co. & M att. Co. Ex. & HVL & Tvl & Mean free path (MEP) \\
\hline 121.78 & 2.351757362 & 0.2734 & 0.294758299 & 0.979055083 & 0.425213934 \\
\hline 344.27 & 0.8468563 & 0.09845 & 0.81855682 & 2.718879225 & 1.180837883 \\
\hline 661.64 & 0.61675568 & 0.0717 & 1.123945871 & 3.733244906 & 1.621387581 \\
\hline 778.9 & 0.570735556 & 0.06635 & 1.214573006 & 4.034267668 & 1.752124937 \\
\hline 964 & 0.514565199 & 0.05982 & 1.347156787 & 4.474651617 & 1.943388325 \\
\hline 1112.4 & 0.478781327 & 0.05566 & 1.447842597 & 4.809084796 & 2.088636176 \\
\hline 1173.23 & 0.466136545 & 0.05419 & 1.4871179 & 4.939539763 & 2.145294142 \\
\hline 1332.51 & 0.437492244 & 0.05086 & 1.584485233 & 5.262950447 & 2.285754809 \\
\hline 1407.24 & 0.425879689 & 0.04951 & 1.627689739 & 5.406456468 & 2.348080985 \\
\hline
\end{tabular}

Table 2: Attenuation properties of $5 \%$ vol $\mathrm{SiC} / \mathrm{Cu}$ composite

\begin{tabular}{|c|c|c|c|c|c|}
\hline $\begin{array}{c}\text { Energy, } \\
\text { keV }\end{array}$ & Linear att. Co. & M att. Co. Ex. & HVL & Tvl & Mean free path (MEP) \\
\hline 121.78 & 2.205818267 & 0.2667 & 0.314259797 & 1.043830325 & 0.453346504 \\
\hline 344.27 & 0.815333951 & 0.09858 & 0.850203771 & 2.823996224 & 1.226491303 \\
\hline 661.64 & 0.595331079 & 0.07198 & 1.164394106 & 3.86759583 & 1.679737602 \\
\hline 778.9 & 0.550999674 & 0.06662 & 1.25807697 & 4.178768355 & 1.814883107 \\
\hline 964 & 0.496908742 & 0.06008 & 1.395024763 & 4.6336476 & 2.012441954 \\
\hline 1112.4 & 0.462336862 & 0.0559 & 1.499339673 & 4.980135023 & 2.162925092 \\
\hline 1173.23 & 0.450178809 & 0.05443 & 1.539832588 & 5.114634353 & 2.221339567 \\
\hline 1332.51 & 0.42247168 & 0.05108 & 1.640820042 & 5.450069456 & 2.367022565 \\
\hline 1407.24 & 0.411223413 & 0.04972 & 1.685701684 & 5.599146175 & 2.431768154 \\
\hline
\end{tabular}




\section{EFFECT OF NANO SIC PARTICLES ON THE CHARACTERIZATION OF SIC/CU NANO-COMPOSITE}

Table 3: Attenuation properties of $10 \%$ vol $\mathrm{SiC} / \mathrm{Cu}$ composite

\begin{tabular}{|r|c|c|c|c|c|}
\hline $\begin{array}{c}\text { Energy, } \\
\text { keV }\end{array}$ & Linear att. Co. & M att. Co. Ex. & HVL & Tvl & Mean free path (MEP) \\
\hline 121.78 & 2.065109983 & 0.2601 & 0.335672195 & 1.114952724 & 0.484235711 \\
\hline 344.27 & 0.783725515 & 0.09871 & 0.884493342 & 2.937890826 & 1.275956928 \\
\hline 661.64 & 0.573721059 & 0.07226 & 1.208252668 & 4.013274334 & 1.743007311 \\
\hline 778.9 & 0.531084993 & 0.06689 & 1.305252471 & 4.335464246 & 1.882937783 \\
\hline 964 & 0.479000712 & 0.06033 & 1.447179476 & 4.806882205 & 2.087679568 \\
\hline 1112.4 & 0.445733466 & 0.05614 & 1.555189487 & 5.165643096 & 2.243493201 \\
\hline 1173.23 & 0.433982744 & 0.05466 & 1.597298533 & 5.30551049 & 2.304239084 \\
\hline 1332.51 & 0.407305429 & 0.0513 & 1.701916916 & 5.653005914 & 2.455160006 \\
\hline 1407.24 & 0.396428072 & 0.04993 & 1.748614817 & 5.80811543 & 2.522525702 \\
\hline
\end{tabular}

Table 4: Attenuation properties of $15 \%$ vol $\mathrm{SiC} / \mathrm{Cu}$ composite

\begin{tabular}{|c|c|c|c|c|c|}
\hline $\begin{array}{c}\text { Energy, } \\
\text { keV }\end{array}$ & Linear att. Co. & M att. Co. Ex. & HVL & Tvl & Mean free path (MEP \\
\hline 121.78 & 2.065109983 & 0.2601 & 0.335672195 & 1.114952724 & 0.484235711 \\
\hline 344.27 & 0.783725515 & 0.09871 & 0.884493342 & 2.937890826 & 1.275956928 \\
\hline 661.64 & 0.573721059 & 0.07226 & 1.208252668 & 4.013274334 & 1.743007311 \\
\hline 778.9 & 0.531084993 & 0.06689 & 1.305252471 & 4.335464246 & 1.882937783 \\
\hline 964 & 0.479000712 & 0.06033 & 1.447179476 & 4.806882205 & 2.087679568 \\
\hline 1112.4 & 0.445733466 & 0.05614 & 1.555189487 & 5.165643096 & 2.243493201 \\
\hline 1173.23 & 0.433982744 & 0.05466 & 1.597298533 & 5.30551049 & 2.304239084 \\
\hline 1332.51 & 0.407305429 & 0.0513 & 1.701916916 & 5.653005914 & 2.455160006 \\
\hline 1407.24 & 0.396428072 & 0.04993 & 1.748614817 & 5.80811543 & 2.522525702 \\
\hline
\end{tabular}

Table 5: Attenuation properties of $15 \%$ vol $\mathrm{SiC} / \mathrm{Cu}$ composite

\begin{tabular}{|c|c|c|c|c|c|}
\hline $\begin{array}{c}\text { Energy, } \\
\text { keV }\end{array}$ & Linear att. Co. & M att. Co. Ex. & HVL & Tvl & Mean free path (MEP \\
\hline 121.78 & 2.065109983 & 0.2601 & 0.335672195 & 1.114952724 & 0.484235711 \\
\hline 344.27 & 0.783725515 & 0.09871 & 0.884493342 & 2.937890826 & 1.275956928 \\
\hline 661.64 & 0.573721059 & 0.07226 & 1.208252668 & 4.013274334 & 1.743007311 \\
\hline 778.9 & 0.531084993 & 0.06689 & 1.305252471 & 4.335464246 & 1.882937783 \\
\hline 964 & 0.479000712 & 0.06033 & 1.447179476 & 4.806882205 & 2.087679568 \\
\hline 1112.4 & 0.445733466 & 0.05614 & 1.555189487 & 5.165643096 & 2.243493201 \\
\hline 1173.23 & 0.433982744 & 0.05466 & 1.597298533 & 5.30551049 & 2.304239084 \\
\hline 1332.51 & 0.407305429 & 0.0513 & 1.701916916 & 5.653005914 & 2.455160006 \\
\hline 1407.24 & 0.396428072 & 0.04993 & 1.748614817 & 5.80811543 & 2.522525702 \\
\hline
\end{tabular}

4.

\section{CONCLUSIONS}

The effect of $\mathrm{SiC}$ on the characterization of $\mathrm{Cu}$ was investigated. The following main observations were made from this study:

1) The grain structure of the copper matrix was reduced with increasing $\mathrm{SiC}$ nano-particles. 


\section{EFFECT OF NANO SIC PARTICLES ON THE CHARACTERIZATION OF SIC/CU NANO-COMPOSITE}

2) The erosion resistance of $\mathrm{Cu}$ in oil environment was improved by increasing nano-SiC content.

3) The dominant abrasion mechanism of pure $\mathrm{Cu}$ belongs to the abrasive mechanism while $\mathrm{SiC} / \mathrm{Cu}$ composites with $5 \mathrm{SiC}$ (vol \%) suffers from plastic deformation and adhesive wear in several places. Increasing the $\mathrm{SiC}$ to $20 \mathrm{SiC}$ (vol \%), both the plastic deformation and adhesive wear decreased greatly.

4) Incorporation of $\mathrm{SiC}$ into $\mathrm{Cu}$ matrix did not change the nuclear properties of $\mathrm{Cu}$.

\section{REFERENCES}

[1] Burkart, W.2005. Introductoin: Status report on fusion research, Nucl. Fusion. 45 (2005). https://doi.org/10.1088/0029-5515/45/10A/E01.

[2] El-Guebaly, L.A. 2010. Fifty years of magnetic fusion research (1958-2008): Brief historical overview and discussion of future trends, Energies. 3 (2010) 1067-1086. https://doi.org/10.3390/en30601067.

[3] Ghodke, S.R., Dutta, B.K., Durgaprasad, P. V. 2020. Analytical development and experimental verification of empirical correlations to determine mechanical properties of copper alloys using small punch test data, Fusion Eng. Des. 159 (2020) 111786. https://doi.org/10.1016/j.fusengdes.2020.111786.

[4] Butterworth, G.J., Forty, B.A. 1992. A survey of the properties of copper alloys for use as fusion reactor materials, J. Nucl. Mater. 189 (1992) 237-276.https://doi.org/10.1016/0022-3115(92)90381-T.

[5] Akbarpour,M.R., Najafi, M., Alipour S., Kim H.S. 2019. Hardness, wear and friction characteristics of nanostructured $\mathrm{Cu}-\mathrm{SiC}$ nanocomposites fabricated by powder metallurgy route, Mater. Today Commun. 18 (2019) 25-31. https://doi.org/10.1016/j.mtcomm.2018.11.001.

[6] Huang, B., Hishinuma, Y., Noto, H., Kasada, R., Oono, N., Ukai, S., Muroga, T. 2018. In-situ fabrication of yttria dispersed copper alloys through MA-HIP process, Nucl. Mater. Energy. 16 (2018) 168-174. https://doi.org/10.1016/j.nme.2018.06.024.

[7] Aghamiri,S.M., Oono, N., Ukai, S., Kasada, R., Noto, H., Hishinuma, Y., Muroga, T.2018. Microstructure and mechanical properties of mechanically alloyed ODS copper alloy for fusion material application, Nucl. Mater. Energy. 15 (2018) 17-22. https://doi.org/10.1016/j.nme.2018.05.019.

[8] Shaik, M.A., Golla, B.R.2020. Two body abrasion wear behaviour of $\mathrm{Cu}-\mathrm{ZrB} 2$ composites against SiC emery paper, Wear. 450-451 (2020) 203260. https://doi.org/10.1016/j.wear.2020.203260.

[9] Metwally, M.A., Sadawy, M.M., Ghanem, M. 2018. The Egyptian International Journal of Engineering Sciences and Technology, Effect of SiC ( p ) Content on the Corrosion Behavior of Nano SiC ( p ) / Cu Composites, 26 (2018) 22-28. https://doi: 10.21608/eijest.2018.97259

[10] Ming, H., Yunlong, Z., Lili, T., Lin, S., Jing, G., Peiling, D. 2015. Surface modifying of SiC particles and performance analysis of $\mathrm{SiCp} / \mathrm{Cu}$ composites, Appl. Surf. Sci. 332 (2015) 720-725. https://doi.org/10.1016/j.apsusc.2015.01.130.

[11] Efe, G.C., Altinsoy, I., Yener, T., Ipek, M., Zeytin, S., Bindal, C. 2010. Characterization of cemented Cu $\begin{array}{lllllll}\text { matrix composites reinforced with } \mathrm{SiC}, & \text { Vacuum. } & 85 & \text { (2010) }\end{array}$ https://doi.org/10.1016/j.vacuum.2010.09.009.

[12] M.A. Metwally, M.M. Sadawy, M. Ghanem, I.G.E.- Batanony, The Role of Nano-SiC on Microstructure and Tribo-logical Properties of $\mathrm{SiC} / \mathrm{Cu}$ Nano-Composite, J. Eng. Res. Reports. 15 (2020) 35-44. https://doi.org/10.9734/jerr/2020/v15i417153.

[13] Sadawy, M.M., El Shazly, R.M. 2019. Nuclear radiation shielding effectiveness and corrosion behavior of some steel alloys for nuclear reactor systems, Def. Technol. 15 (2019) 621-628. https://doi.org/10.1016/j.dt.2019.04.001.

[14] Metwally, M., Fattah, H. A., Ghanem, M., Batanony, I. 2018. Effect of Sic Content on Dry Sliding Wear Behavior of Nanosized Sic(P)/Cu Composites, J. Al-Azhar Univ. Eng. Sect. 13 (2018) 1260-1267. https://doi.org/10.21608/auej.2018.18937.

[15] J. Berger, MJ; Hubbell, XCOM Photon Cross Sections, Nist. 87 (1987) 26.

[16] El Shazly, R.M., Sadawy, M.M. 2017. Effect of Slag as a Fine Aggregate on Mechanical, Corrosion , and Nuclear Attenuation Properties of Concrete, 5 (2017) 243-250. 